\title{
Use of Cardiac Computed Tomography and Magnetic Resonance Imaging in Case Management of Atrial Fibrillation with Catheter Ablation
}

\author{
Hee-Gone Lee, $\mathrm{MD}^{1}$, Jaemin Shim, MD, PhD², Jong-il Choi, MD, PhD², Young-Hoon Kim, MD, PhD², \\ Yu-Whan Oh, MD, PhD ${ }^{1}$, Sung Ho Hwang, MD, $\mathrm{PhD}^{1}$ \\ ${ }^{1}$ Department of Radiology, Korea University Anam Hospital, Seoul, Korea; ${ }^{2}$ Division of Cardiology, Department of Internal Medicine, Korea \\ University Anam Hospital, Seoul, Korea
}

Atrial fibrillation (AF) is the most common arrhythmia associated with the risk of morbidity and mortality in clinical patients. $\mathrm{AF}$ is considered as an arrhythmia type that develops and progresses through close connection with cardiac structural arrhythmogenic substrates. Since the introduction of catheter ablation-mediated electrical isolation of arrhythmogenic substrates, cardiac imaging indicates improved treatment outcome and prognosis with appropriate candidate selection, ablation catheter guidance, and post-ablation follow-up. Currently, cardiac computed tomography (CCT) and cardiovascular magnetic resonance (CMR) imaging are essential in the case management of AF at both pre-and post-procedural stages of catheter ablation. In this review, we discuss the roles and technical considerations of CCT and CMR imaging in the management of patients with AF undergoing catheter ablation.

Keywords: Computed tomography; Magnetic resonance imaging; Arrhythmia; Atrial fibrillation; Catheter ablation

\section{INTRODUCTION}

Atrial fibrillation (AF) is the most frequent arrhythmia and represents a growing health care problem worldwide (1). AF is characterized by the presence of an irregular ventricular interval and absence of distinct organized atrial activity (2). Studies on the pathophysiologic aspects of AF suggest that focal electrical activation induces and maintains AF through an arrhythmogenic substrate $(3,4)$.

Received November 6, 2018; accepted after revision January 21, 2019.

This study was supported by Basic Science Research Program through the National Research Foundation of Korea (NRF) funded by the Ministry of Education (2018R1D1A1A02085358).

Corresponding author: Sung Ho Hwang, MD, PhD, Department of Radiology, Korea University Anam Hospital, 73 Inchon-ro, Seongbuk-gu, Seoul 02841, Korea.

- Tel: (822) 920-6289 - Fax: (822) 929-3796

- E-mail: sungho.hwng@gmail.com

This is an Open Access article distributed under the terms of the Creative Commons Attribution Non-Commercial License (https://creativecommons.org/licenses/by-nc/4.0) which permits unrestricted non-commercial use, distribution, and reproduction in any medium, provided the original work is properly cited.
Recent increase in the understanding of the mechanism and pathophysiology of AF has led to the development of catheter ablation to isolate electrically arrhythmogenic substrate of AF in the pulmonary vein (PV) and cardiac structures $(5,6)$. Haïssaguerre et al. (7) introduced the first approach to catheter ablation of AF by point ablation of PV in 1994. Since then, multiple approaches have been developed, including the segmental isolation of PV and circumferential ablation of cardiac structures (8). Recently, because of their invasiveness, advanced procedures of catheter ablation require careful decisions regarding appropriate candidate selection, catheter ablation strategies, and treatment monitoring because of their invasiveness (1).

With regard to successful catheter ablation of AF, cardiac computed tomography (CCT) and cardiovascular magnetic resonance (CMR) imaging enable appropriate candidate selection, guidance of the ablation catheter, and follow-up after catheter ablation $(9,10)$. This overview discusses the role of CCT and CMR imaging at the pre- and post-procedural stages of catheter ablation of AF. 


\section{Pre-Procedural Stage}

Before catheter ablation of AF, CCT, and CMR imaging are performed for the purpose of comprehensive evaluation of the left atrium (LA), left atrial appendage (LAA), left ventricle (LV), and PVs.

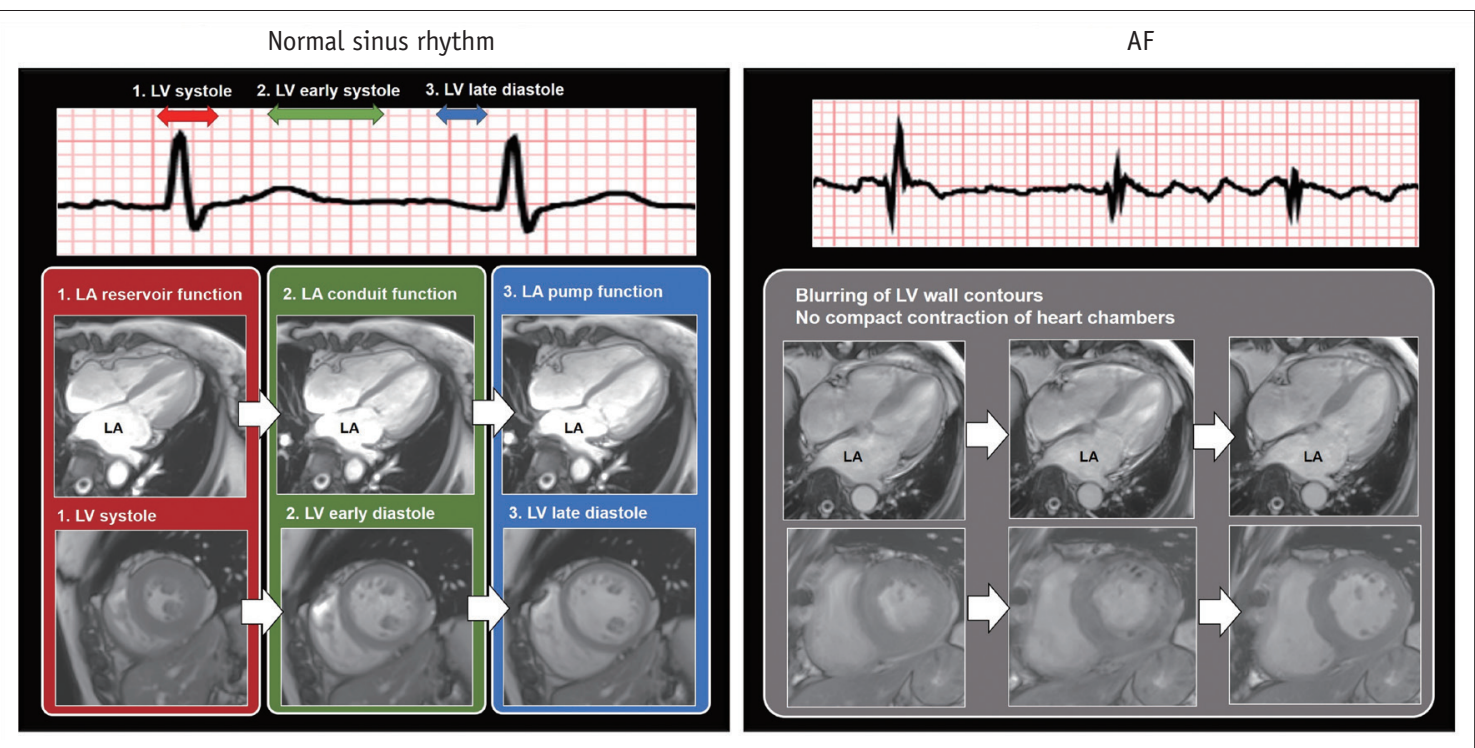

Fig. 1. Function of LA during normal sinus rhythm and during AF. In normal sinus rhythm, LA function consists of 1) LA reservoir function at LV systole, 2) LA conduit function during early LV diastole, and 3) LA pump function at late LV diastole. In contrast to sinus rhythm, AF results in rapid and inconsistent heart motion, which may be associated with blurring heart contours on cardiac images. $A F=$ atrial fibrillation, $L A=$ left atrium, $\mathrm{LV}=$ left ventricle

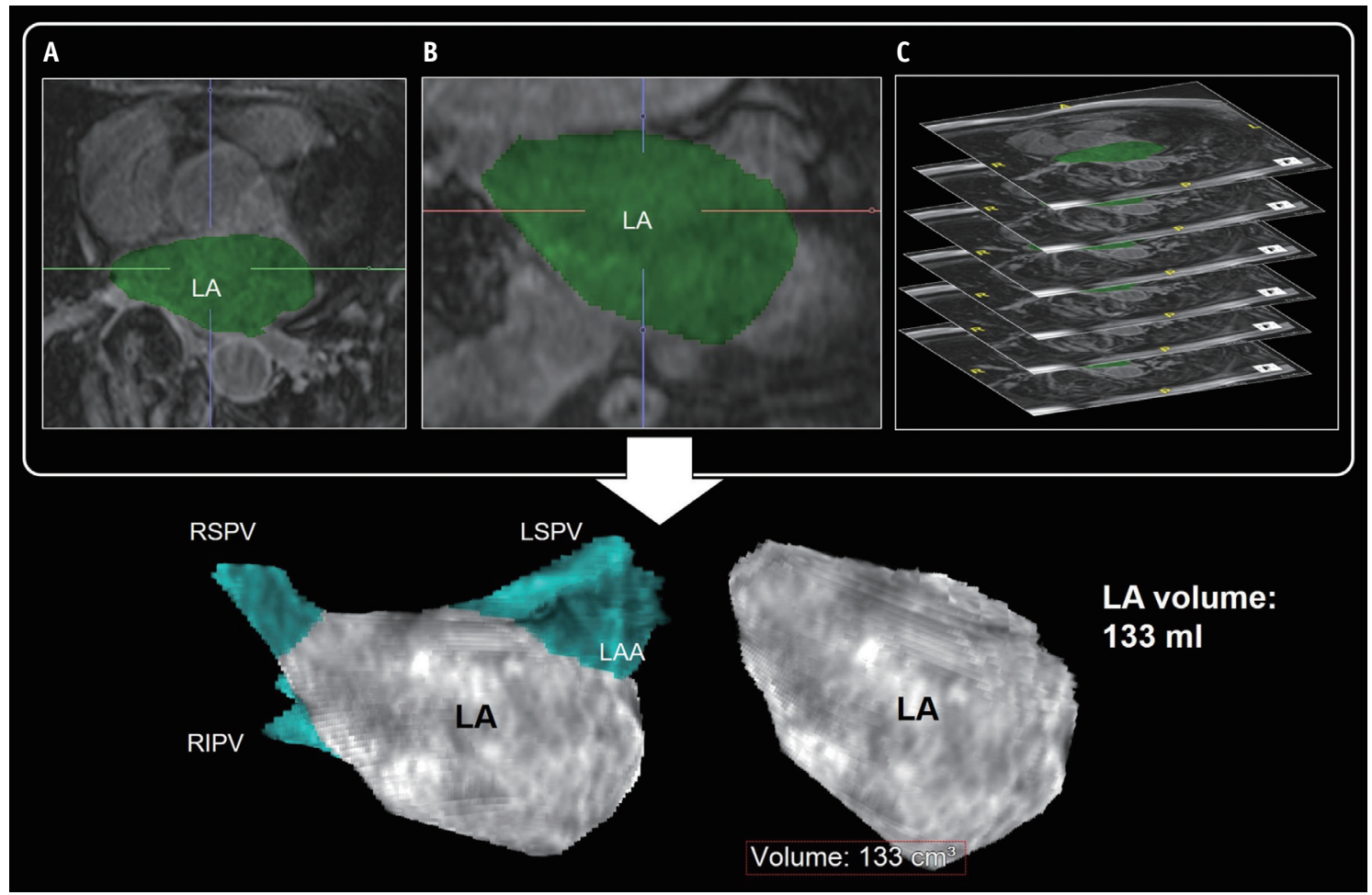

Fig. 2. Evaluation of LA volume by 3D techniques of CMR imaging.

Transverse (A) and coronal (B) reformatting of CMR images helps determination of LA chamber areas. Sum of LA chamber areas (green) on thin slice CMR images $(C)$ can be considered as measurement of actual LA volume. PVs and LAA are usually excluded in LA volume measurement using 3D LA model. $C M R=$ cardiovascular magnetic resonance, $L A A=$ left atrial appendage, $L S P V=$ left superior pulmonary vein, $P V s=$ pulmonary veins, $\mathrm{RIPV}=$ right inferior pulmonary vein, $\mathrm{RSPV}=$ right superior pulmonary vein, $3 \mathrm{D}=$ three-dimensional 


\section{The $L A$}

The LA is a bridge chamber between the LV and PVs (11). The presence of enlargement, dysfunction, and fibrosis of the LA indicates the progression of LA remodeling (12). Evaluation of the LA size, function, and fibrosis by CCT and CMR is performed to assess the LA remodeling in patients with AF.

The LA remodeling by chronic hemodynamic stress is a predictor of adverse cardiovascular outcome and AF recurrence after catheter ablation $(13,14)$. Severe enlargement and impairment of LA reflects the duration and severity of chronic hemodynamic stress to the LA. The LA size can be determined by the LA diameter, area, and volume $(9,15,16)$. and the LA function can be represented commonly by the change of LA size during the cardiac cycle. In normal sinus rhythm, the LA has three mechanical functions: 1) LA reservoir function that reflects the $L A$ filling during LV systole, 2) LA conduit function just before the onset of LA contraction, and 3) LA pump function during LV late diastole (16) (Fig. 1). Importantly, AF itself can cause loss of modulation and adaptation in LA function, which may interrupt the LA function. Electrocardiography (ECG) gating allows delineation of the changes of cardiac structures during the entire cardiac cycle by CCT and CMR ( 9 , 10). In general, the LA diameter and area are measured in the four-chamber images at end-systolic phase of maximum value of the LA size. The LA volume can be measured using the area-length biplane or prolate ellipsoid method, both of which are less accurate than the modified Simpson method (16). Three-dimensional (3D) reformatting techniques for CCT and CMR imaging have improved the accuracy of LA volume quantification $(16,17)$ (Fig. 2).

The LA fibrosis is a hallmark of LA remodeling as well as an indicator of the arrhythmogenic substrate of $\mathrm{AF}$ (18). A prospective multicenter study demonstrates an association between the degree of the LA fibrosis and AF recurrence after catheter ablation (19). CMR imaging has the potential to delineate the LA fibrosis with 3D lategadolinium enhancement (LGE) CMR technique (20) (Fig. 3). In LGE-CMR imaging, the LA fibrosis with accumulation of gadolinium contrast appears as bright-signal intensity of LGE on T1-weighted sequences. LGE-CMR imaging for the LA

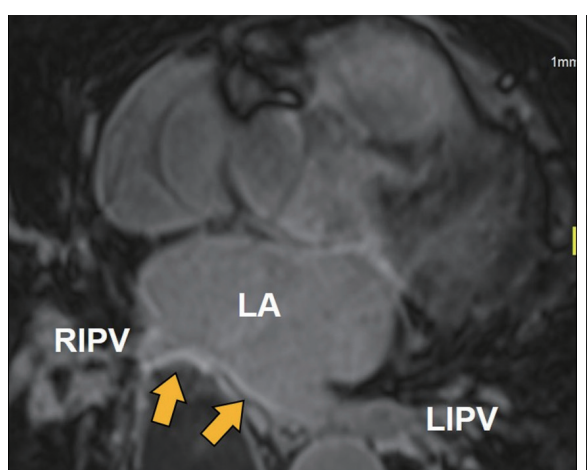

A

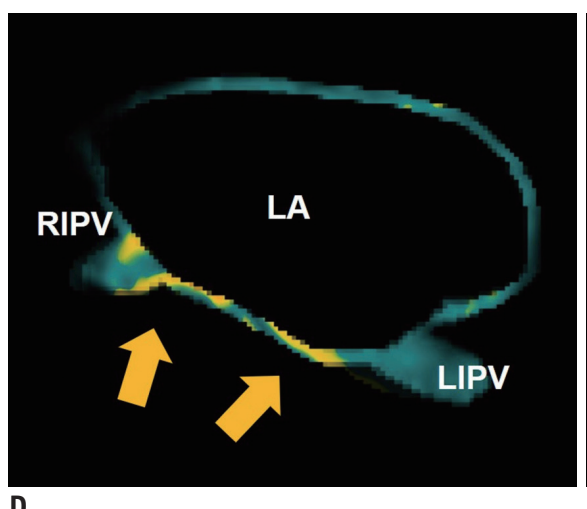

D

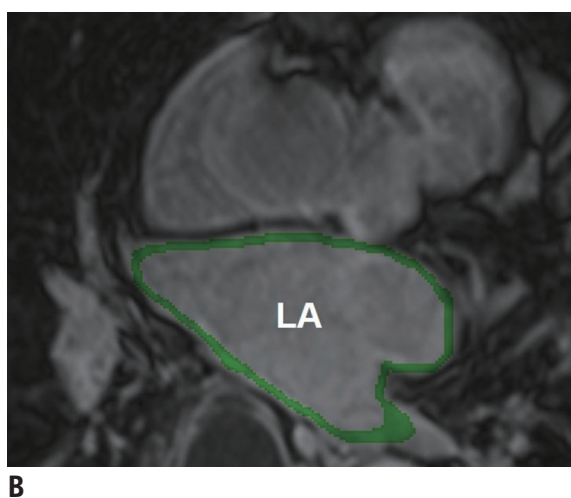

B

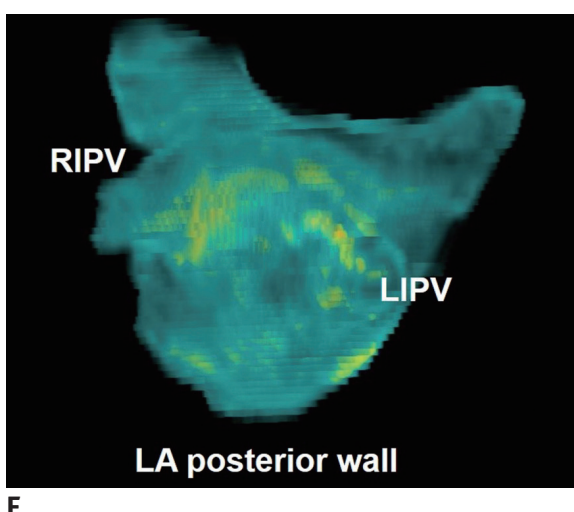

E
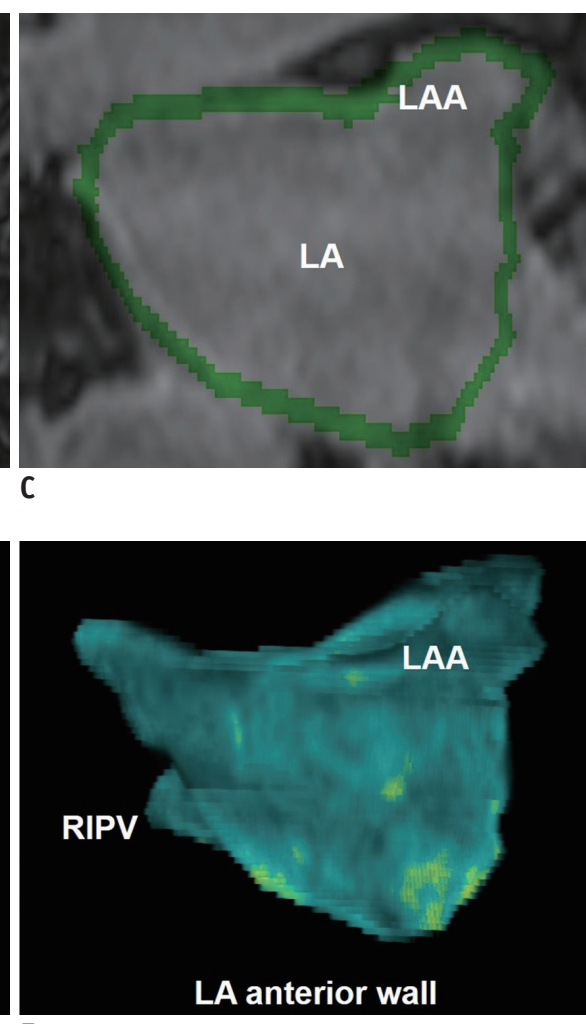

$\mathbf{F}$

Fig. 3. LA fibrosis determined with 3D LGE-CMR imaging.

3D LGE-CMR image (A) with excellent spatial resolution describes thin LA wall and hyperenhancement areas (arrows) in detail. Segmentation of thin LA wall with slice thickness of $<2 \mathrm{~mm}(\mathbf{B}, \mathbf{C})$ can reconstruct 3D LA models (D-F) which show tissue composition of LA wall in basis of signal intensity of LGE (arrows, yellow foci). LGE = late-gadolinium enhancement, LIPV = left inferior pulmonary vein 
fibrosis needs high resolution and thin-section 3D images acquired during free breathing using both respiratory and ECG-gating (21). Oakes et al. (20) report that the LALGE correlates strongly with the level of low endocardial bipolar voltage as in the LA fibrosis. However, despite its useful potential, several technical limitations involving the limited spatial resolution of LGE-CMR imaging fluid filling, the underlying rhythm, and the imaging modalities etc., the complicated segmentation of the thin wall, and the various algorithms of signal intensity to define the LA fibrosis should be considered.

\section{The LAA}

The LAA as a remnant of the original embryonic LA has a pouch-like extension from the main body of the LA. The LAA is a common site of intracardiac thrombus formation and is significantly associated with the hemodynamic status of the LA.

During development of an AF episode, cardiac thrombus formation occurs commonly within the LAA of reduced contractility (22). The LAA thrombus is an absolute contraindication of catheter ablation (23). Transesophageal echocardiography (TEE) is a gold standard for identification of the LAA thrombus (24). Currently, CCT is recommended as a convenient alternative to TEE because the esophageal passage of the TEE probe may cause discomfort to the patient. Patel et al. (25) reported that CCT showed a negative predictive value of $100 \%$ for exclusion of the LAA thrombus. Although incomplete filling of contrast agent within the LAA may mimic the presence of thrombus on CCT images, addition of delayed computed tomography (CT) scan can improve the specificity to $99 \%$ in the diagnosis of the LAA thrombus (9).

The LAA is an actively contracting structure, which may

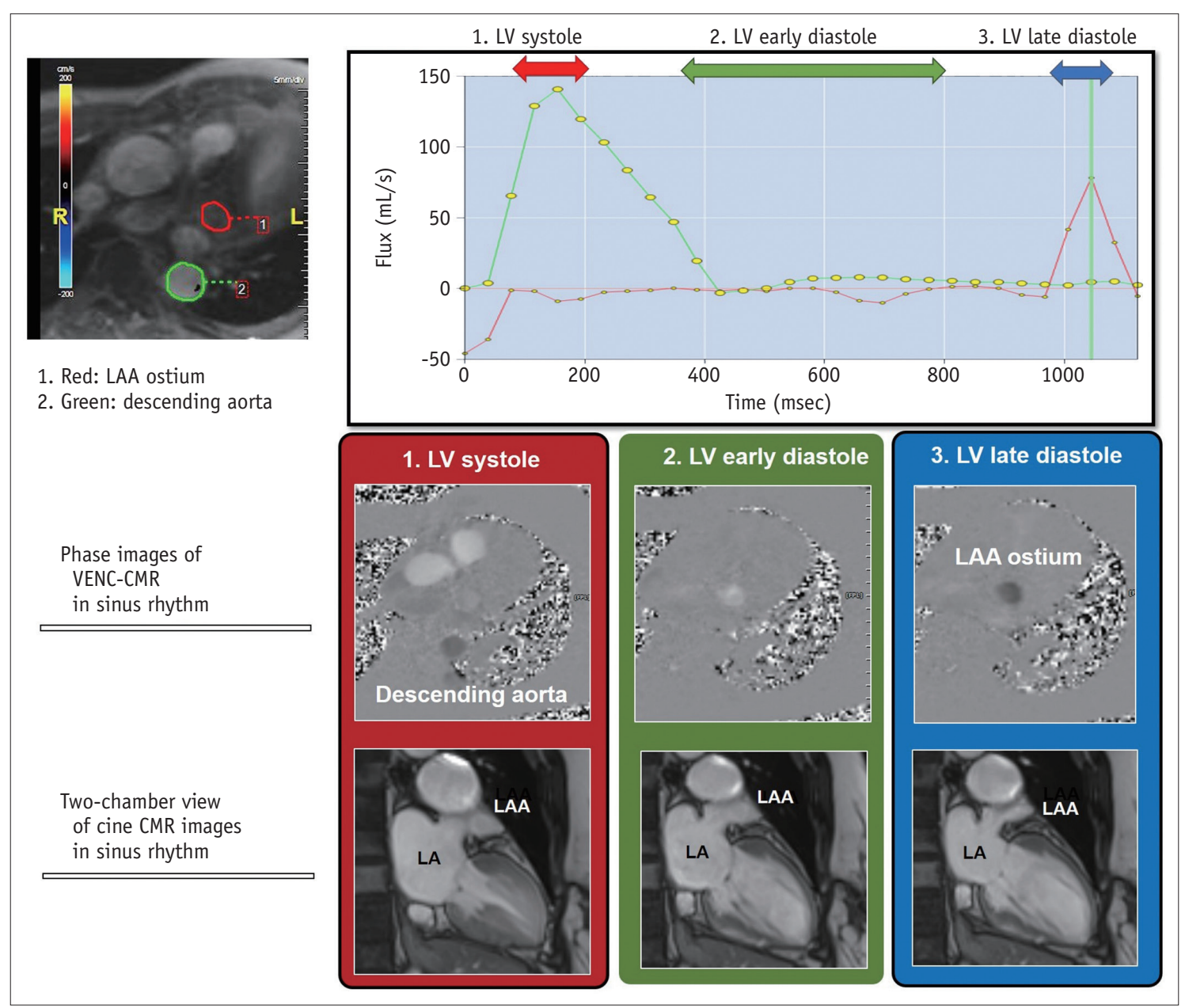

Fig. 4. Evaluation of LAA function by CMR imaging. VENC CMR imaging can quantify blood flow through LAA ostium. Mechanically, active emptying of LAA can be represented mechanically by active contraction of LAA. It can be measured by peak blood flux (in $\mathrm{mL} / \mathrm{s}$ ) which develop at LV late diastole in sinus rhythm. VENC = velocity-encoded 
play an important role in cardiac hemodynamics. The LAA blood flow velocity through the LAA ostium is the preferred method to assess the LAA function. The four-phasic pattern of the LAA blood flow at sinus rhythm consists of the following: 1) Early diastolic passive emptying, 2) late diastolic active emptying, 3) the LAA relaxation, and 4) systolic reflection. The decreased LAA blood flow at late diastolic active emptying is associated with the LA hypertension and blood stasis which interrupt the blood flow from the LAA to LA chamber. Velocity-encoded (VENC) CMR is a cine phase contrast imaging technique that employs a bipolar gradient pulse to encode the velocity of moving protons (26). VENC-CMR imaging uniquely represents the late diastolic active emptying of LAA with quantification of blood flow through the LAA ostium (27) (Fig. 4). Hwang et al. (28) reported that the quantification of active emptying of LAA by VENC-CMR may be useful in assessing the LA hypertension in patients with AF.

\section{The LV}

The LV is the thickest of the four heart chambers and is located below the LA. The progression to permanent AF may have adverse effects on the myocardium of LV wall, which can result in remodeling of both the LA and LV. From the view-point of catheter ablation, the irreversible LV remodeling with myocardial fibrosis may reduce the effectiveness of treatment despite the termination of $\mathrm{AF}$ after catheter ablation. The LV dysfunction and fibrosis are considered as the major findings of the LV remodeling related to $\mathrm{AF}$.

Reduced LV systolic function is associated with stroke in patients with AF (29). Beyond LV systolic function, LV diastolic dysfunction resulting from fibrotic infiltration of the myocardium may in turn perpetuate AF due to the resulting LA wall stress and remodeling (30). The LV function is traditionally expressed as LV end-diastolic volume, LV end-systolic volume, and LV ejection fraction, which can be assessed by CCT and CMR imaging (31).

LV myocardial fibrosis may occur secondary to irregular and fast LV contraction in the setting of long-standing AF (32). In general, the presence of LV myocardial fibrosis can be determined with LV-LGE of CMR imaging. Only $2 \%$ of patients with AF showed the presence of LV-LGE without myocardial infarction (33). Interestingly, the LV-LGE was a predictor of functional recovery of the LV in patients with AF and LV dysfunction undergoing catheter ablation (34).

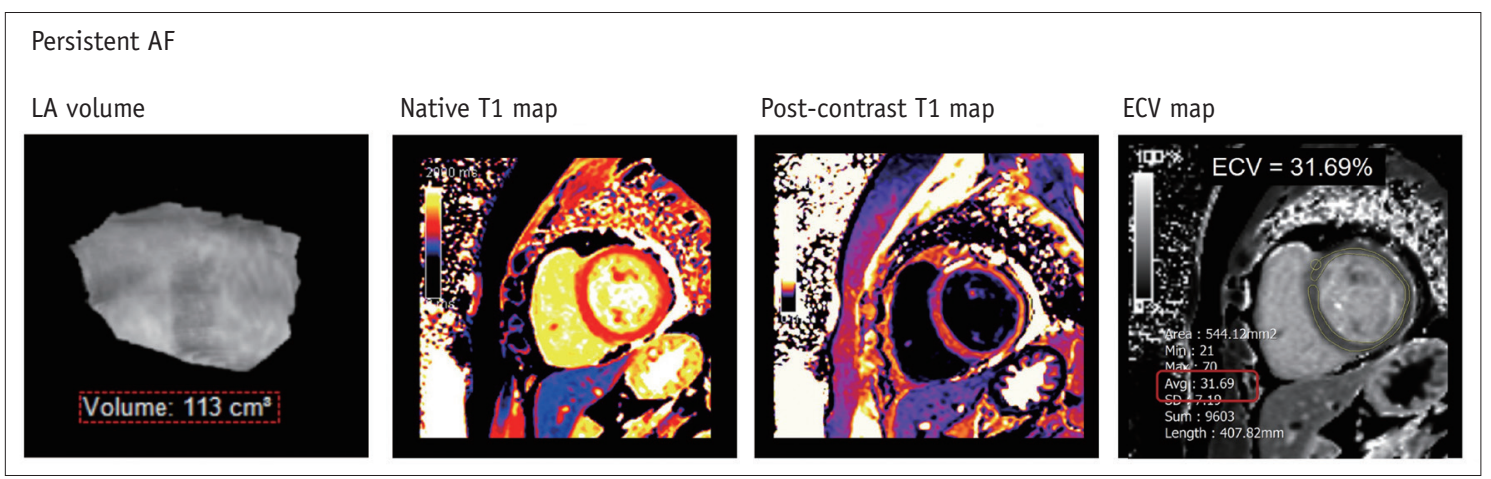

Paroxysmal AF

LA volume

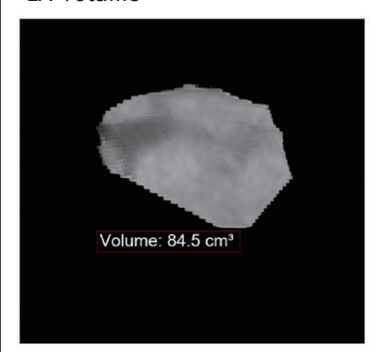

Native T1 map

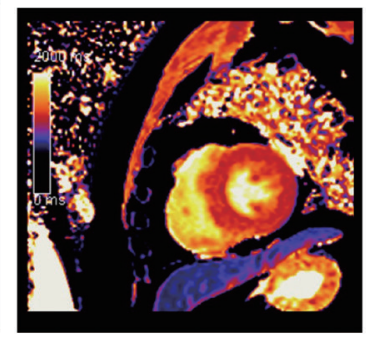

Post-contrast T1 map

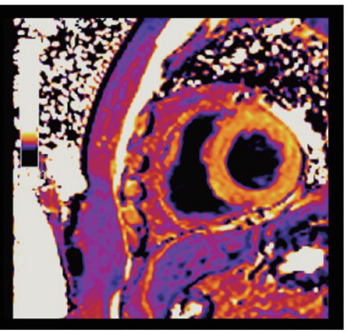

ECV map

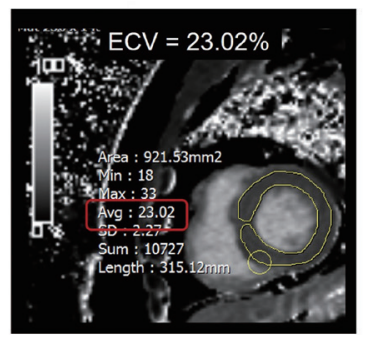

Fig. 5. LV myocardial remodeling by CMR imaging in patient with AF.

Recent CMR technique provides assessment of myocardial ECV in LV wall derived from pre- and post-contrast T1 maps in patients with AF. In 40-year-old man with persistent AF, ECV map shows mean LV myocardial ECV of $31.69 \%$. Usually, it has been widely accepted that mean LV myocardial ECV is less than $28 \%$ in healthy individuals without definite cardiomyopathy. ECV = extracellular volume fraction 
The LV-LGE may be a significant independent predictor of $A F$ recurrence after catheter ablation (35). In the setting of persistent AF, diffuse myocardial fibrosis of the LV wall may occur as a result of tachycardia-mediated cardiomyopathy (36) (Fig. 5). Recent CMR techniques allow the quantification of LV myocardial extracellular volume fraction (ECV), which is derived from pre- and post-contrast T1 measures (37). Neilan et al. (38) reported that the expansion of LV myocardial ECV through CMR imaging was associated with the risk of recurrent $\mathrm{AF}$ after catheter ablation.

\section{The PVS}

The myocardial muscle sleeves extending from the LA into the PVs are vital sources of AF triggers (23). The PVs are first target of catheter ablation-mediated electrical isolation (1). The typical anatomy comprises the four PVs with separate ostia; in contrast, the atypical PV anatomy mainly comprises an additional right middle PV or common ostium in the left PVs (15) (Fig. 6). The accessory ostia are smaller than normal (15). The PV ostial diameters undergo change during the cardiac cycle. The PVs are typically imaged at the cardiac late systolic phase, when they have the largest caliber.

The use of electroanatomic mapping systems to guide such catheter-based procedures requires CCT or CMR imaging to delineate the PV anatomy in detail (30). CCT images are acquired at end expiration to enable mapping in the electrophysiology laboratory. ECG gating is preferred to avoid motion artifacts. In patients with high heart rates and in large patients, retrospective ECG gating may be required. Non-ECG-gated helical scans are used in patients with AF and high heart rates (39). Motion artifacts with this technique are negligible and do not compromise the ability to make a diagnosis. Popular CMR technique for delineation of PVs and various cardiac structures is that of time-resolved magnetic resonance angiography (TR-MRA), which involves rapid sequential imaging of an anatomic volume during the luminal transit of a contrast bolus (40, 41) (Fig. 7). TR-MRA based on T1-weighted gradient echo
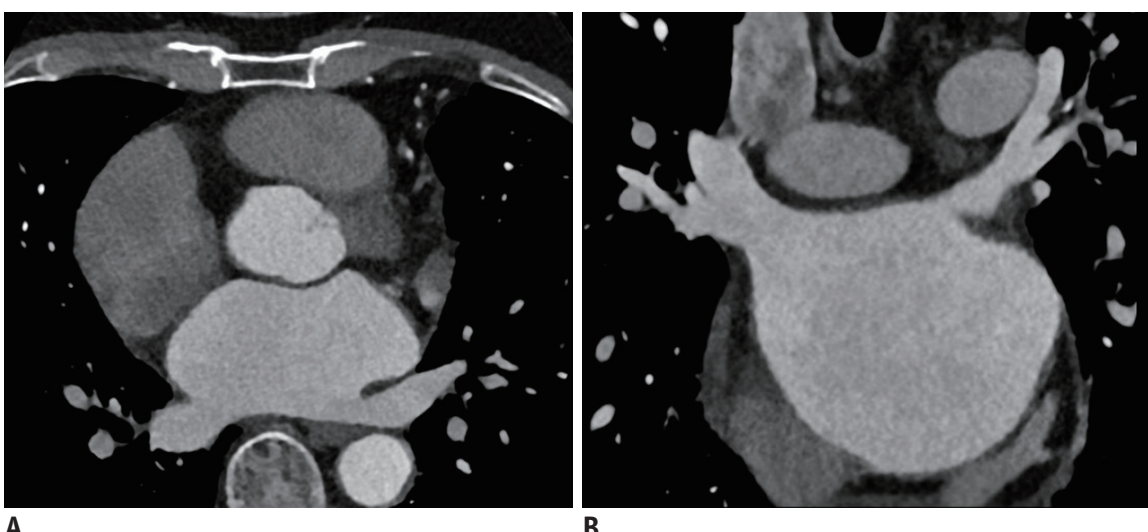

B
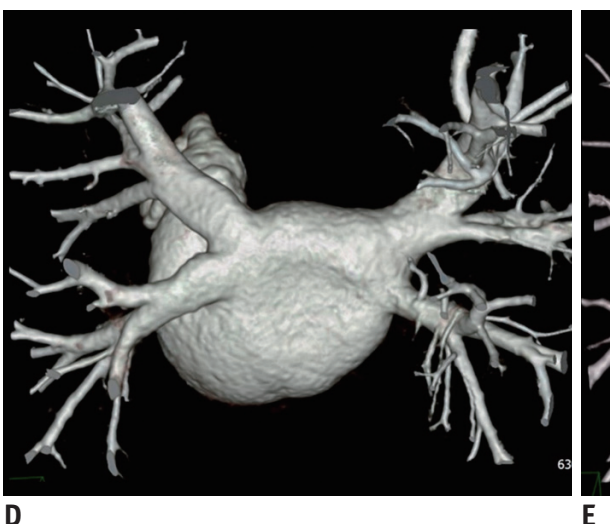
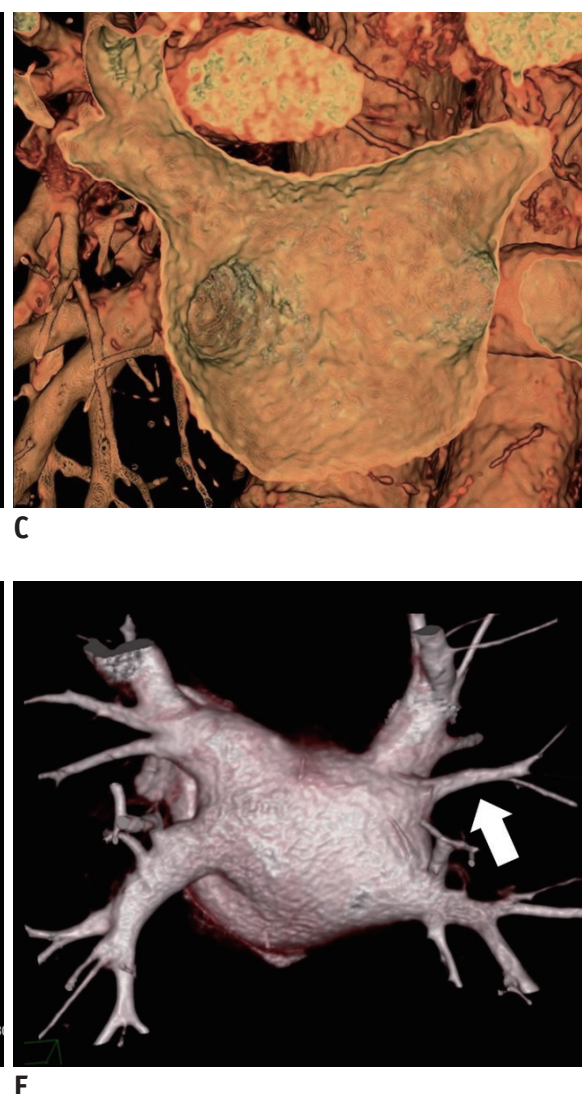

Fig. 6. PV anatomy and LA by CCT images.

Isotropic voxel data from CCT scan can be reformatted into transverse (A) and coronal (B) multiplanar images. 3D volume rendering image (C) of CCT reveals stereoscopic view inside LA chamber and PV ostium. In 3D volume rendering images of PVs, typical anatomy comprises four PVs with separate ostia (D). Atypical PV anatomy mainly comprises common ostia for left PVs (arrow) (E) and additional right middle PV (arrow) (F). CCT = cardiac computed tomography 
sequence is designed based on sufficiently short repetition time to allow repeated imaging at temporal resolutions of 1-2 seconds per frame (40).

\section{Image Integration and Electroanatomic Mapping}

Using CCT and CMR volumetric data sets, a 3D cardiac model can be reconstructed. The 3D cardiac model can be referenced in the electrophysiology laboratory for catheter manipulation (42) (Fig. 8). 3D electroanatomic mapping based on imaging volumetric data sets permits tracking of catheter movement and more precise localization of ablation points. Anatomic shells on the models of the cardiac atria are created by moving the catheter along the walls of the 3D cardiac model and recording multiple catheter positions ( 9 , 43). Electrograms and points of interest can be displayed on the $3 \mathrm{D}$ electroanatomic mapping. It has become apparent that the use of $3 \mathrm{D}$ anatomic mapping with image integration may reduce procedure time and shorten radiation exposure.
(43). However, previous randomized studies showed no significant improvement of clinical outcome by image integration in catheter ablation of $\mathrm{AF}(42,44)$.

\section{Post-Procedural Stage}

Regardless of the AF termination after catheter ablation, the catheter ablation of AF itself can have various consequences on cardiac structures such as the ablation-induced simple scar, shrinkage of the LA chamber, enlargement of the LAA, and critical complications. After the catheter ablation of AF, post-procedural CCT and CMR imaging can be performed for assessment of the appropriateness of catheter ablation and early detection of the ablation-related complications.

\section{Ablation-Induced LA Scar and the LA Reverse Remodeling}

Generally, the catheter ablation of AF produces the LA scar along the ablation line as well as the termination of

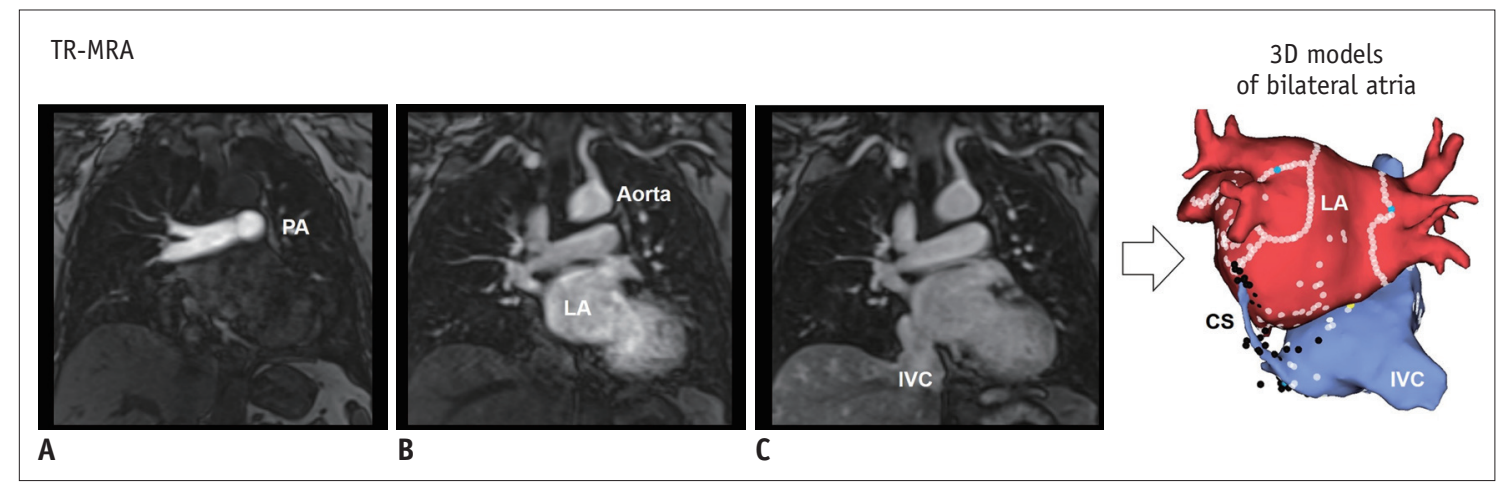

Fig. 7. Evaluation of PV by CMR imaging.

TR-MRA shows sequential contrast enhancement of large vessels from PA (A), through LA and aorta (B), to IVC (C). Multi-phase images by TRMRA allows reconstruction of $3 \mathrm{D}$ models including $C S$, IVC, right atrium and $L A . C S=$ coronary sinus, IVC $=$ inferior vena cava, $P A=$ pulmonary artery, TR-MRA = time-resolved magnetic resonance angiography

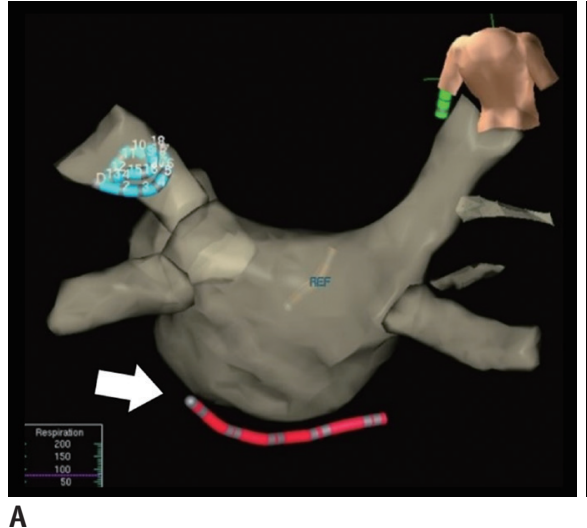

A
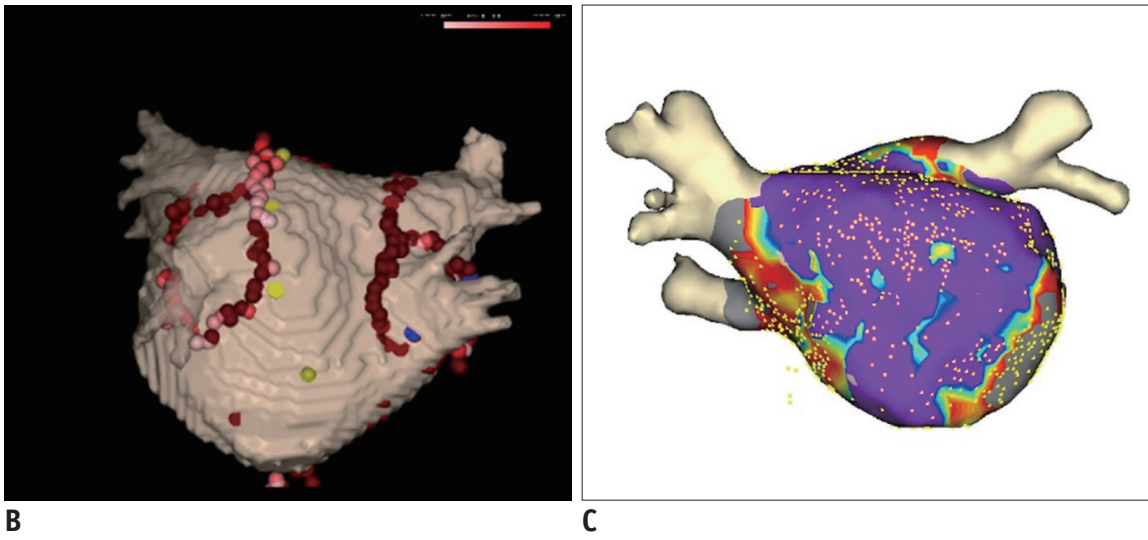

Fig. 8. Electroanatomic mapping.

Electroanatomic maps can help guide catheters (arrow) (A), reveal process of ablation lines (B), and fuse between LA model from cardiac image data and shell of electrophysiologic study (C) during catheter ablation of AF. 
AF. These pathophysiologic processes by catheter ablation can arrest the LA remodeling, and subsequently result in shrinkage of the LA chamber as the LA reverse remodeling. Therefore, the LA reverse remodeling and ablation-induced LA scar are typical changes of the LA structure after the catheter ablation of AF.

Radiofrequency energy generated from the catheter ablation procedure causes permanent lesions as the ablation line surrounding the LA wall with circumferential arrhythmogenic substrate (21). The ablation-induced LA scar by ablation line shows the myocardial stasis of gadolinium contrast agent with ECV expansion. Especially, LGE-CMR imaging enables direct identification and quantification of the ablation line by delayed stasis of gadolinium in the LA wall (45) (Fig. 9). The presence of gaps from incomplete ablation lines has been implicated as one of the reasons for the recurrence of AF. LGE-CMR imaging for the identification of incomplete ablation line by non-invasive approach has useful potential in both the assessment of the catheter ablation efficiency and guidance of the second catheter ablation procedure $(46,47)$.

Catheter ablation commonly results in shrinkage of the enlarged LA chamber defined as the reverse LA remodeling $(14,48)$. Improvement of the LA function after catheter ablation represents the increase in LA contractility with achievement of normal sinus rhythm. However, the LA

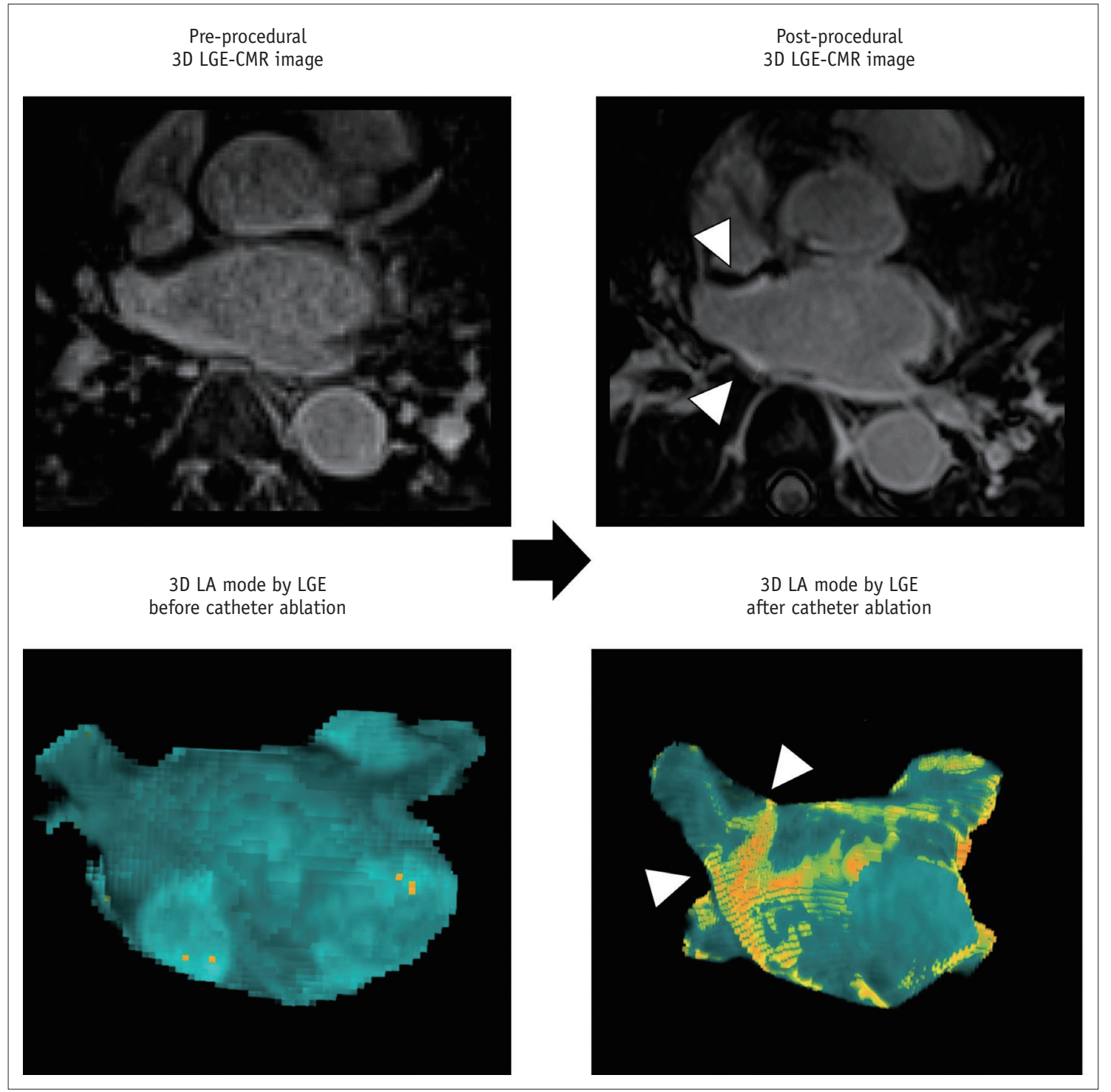

Fig. 9. Ablation-induced LA scar by 3D LGE-CMR imaging. Post-procedural 3D LGE-CMR image shows thick LA wall areas of bright signal intensity (arrowheads) due to ablation-induced LA scar near RSPV. Post-procedural 3D LA model by LGE reveals ablation lines (arrowheads) surrounding LA antrum for electrical isolation of RSPV. 
reverse remodeling with loss of LA contractility can be caused by the ablation-induced LA scar itself. Although the LA reverse remodeling has been considered as a characteristic of successful catheter ablation, the degree of $L A$ reverse remodeling is not associated with the recurrence of AF after catheter ablation.

\section{Enlargement of the $L A A$}

Paradoxically, there is enlargement of the LAA after the catheter ablation of AF (49) (Fig. 10). Recent study using CMR imaging reports that the volume of the LAA increases by $>20 \%$ after the catheter ablation of AF as compared to that before treatment (50). Enlargement of

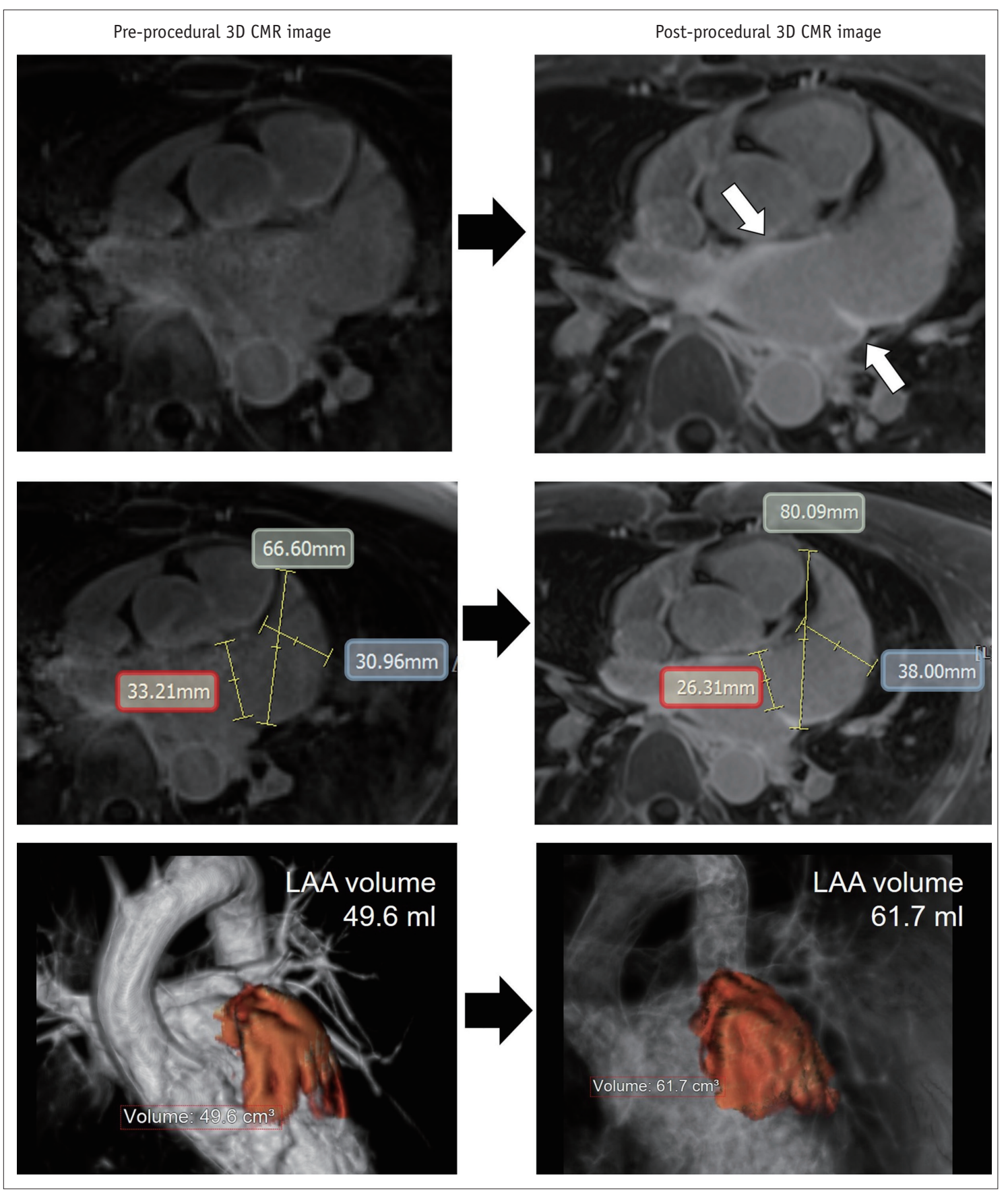

Fig. 10. Enlargement of LAA after catheter ablation of AF. Post-procedural 3D LGE-CMR image shows thick LA wall areas of bright signal intensity (arrows) due to ablation-induced LA scar near ostium of LAA. Compared with pre-procedural CMR images, dimension of LAA ostium (red box) was decreased although chamber of LAA was enlarged. Volume of LAA increased from 49.6-61.7 mL after catheter ablation of AF. 
the LAA after catheter ablation may develop due to the AF recurrence, stiff LA wall by the ablation-induced LA scar, and inappropriate contraction of the LAA (49). Eventually, the development of significant enlargement of the LAA suggests worsening hemodynamics between the LA chamber and LAA (51). Although the unstable hemodynamics in the enlarged LAA is a critical risk factor of thrombus formation, the clinical significance of routine monitoring of the LAA after catheter ablation is still uncertain.

\section{Pulmonary Vein Stenosis}

Pulmonary venous stenosis (PVSt) is defined as the reduction in $\mathrm{PV}$ diameter of $>50 \%$ compared to that before the catheter ablation of AF (52). PVSt may result in focal lung edema, veno-occlusive disease, lung parenchymal hemorrhage, and venous thrombosis (53) (Fig. 11). To confirm the diagnosis, CT is the technique of choice, although CMR provides the same information without the need for radiation or iodinated contrast (54). Chest CT imaging has an important role to diagnose PVSt and evaluate risk factors, such as the PV ostia and left inferior PV location. Balloon angioplasty and stent insertion can be applied to treat patients with significant PVSt after the catheter ablation of AF (55).

\section{Atrioesophageal Fistula}

Atrioesophageal fistula (AEF) after catheter ablation is rare, but fatal complication from cerebrovascular events due to air embolism (56). Extensive catheter ablation targeting the PVs and posterior LA wall may increase the prevalence of AEF. Esophagus is most susceptible to injury because it is closest to the areas of endocardial ablation. AEF usually develops
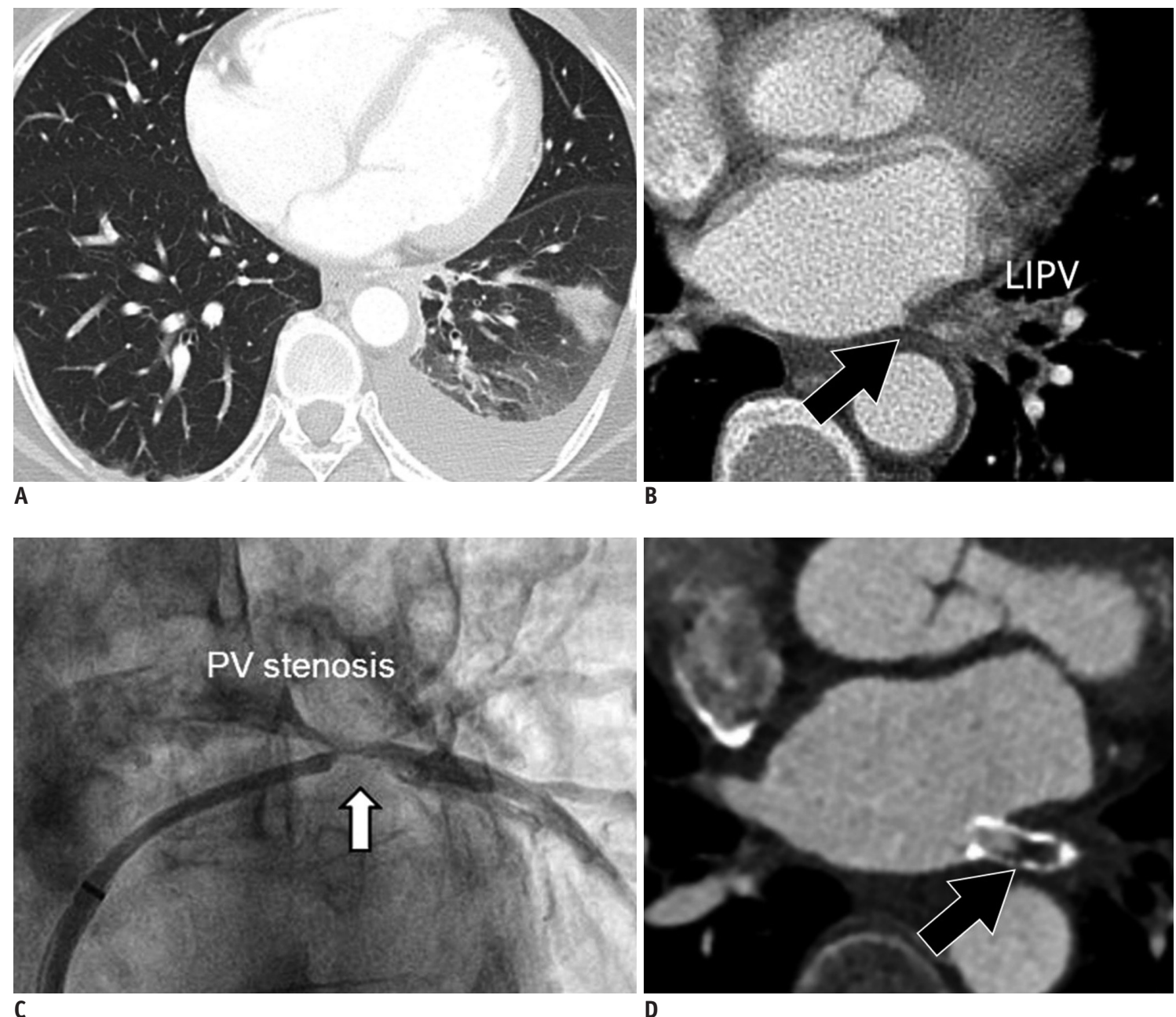

Fig. 11. PV stenosis in 50-year-old male who underwent catheter ablation of AF.

Transverse chest CT image (A) shows interstitial edema and consolidation of left lung lower lobe. Chest CT image (B) with mediastinal window set shows interstitial edema and luminal narrowing of LIPV (arrow). Conventional angiography (C) also shows focal narrowing of LIPV as PV stenosis (arrow). Six-month follow-up cardiac CT image (D) shows in-stent restenosis (arrow) after stent insertion for PV stenosis. 


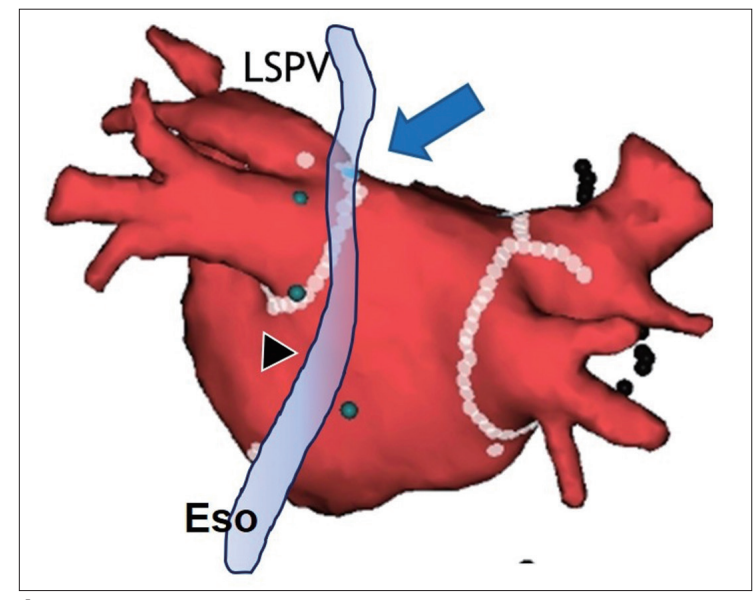

A

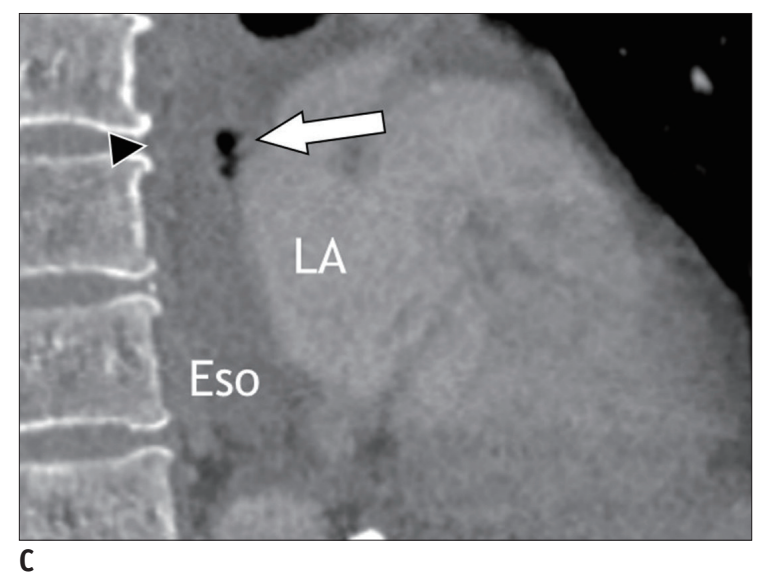

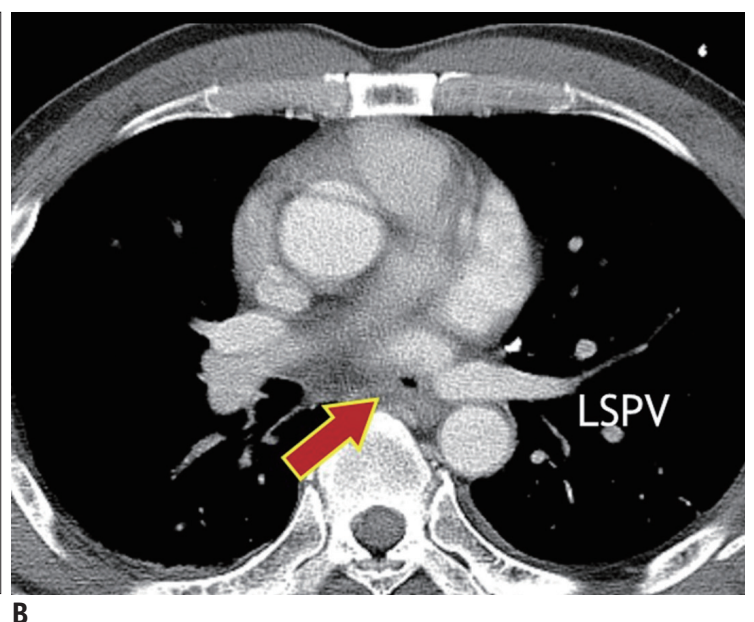

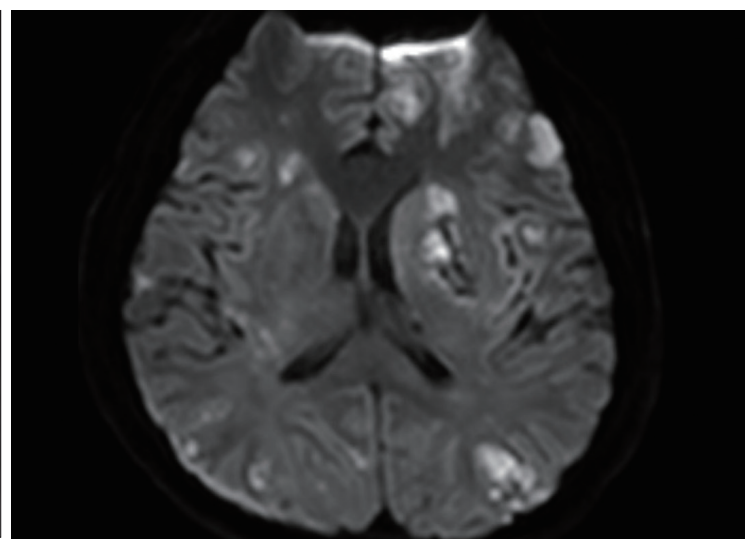

D

Fig. 12. Atrioesophageal fistula in 43-year-old male who underwent catheter ablation of AF.

Electroanatomic map (A) shows multiple ablation points forming antrum ablation line (arrow) for electrical isolation of LSPV just anterior to Eso (arrowhead). Transverse chest CT image (B) shows small air-bubble (arrow) near LSPV. Sagittal reformatting image of chest CT (C) shows airbubbles (arrow) between ESo (arrowhead) and LA. Fluid-attenuated inversion recovery magnetic resonance image of brain (D) reveals embolic stroke with multiple foci of bright signal intensity in bilateral cerebral hemispheres. Eso $=$ esophagus

at 1-4 weeks after the catheter ablation of AF (1). TEE and esophagoscopy are contraindicated in case of suspected AEF. Contrast-enhanced chest $\mathrm{CT}$ is the imaging modality of choice, and the specific CT findings of AEF include airbubbles at the mediastinum or LA near the esophagus (57) (Fig. 12). Immediate surgery is needed to prevent serious and fatal outcomes due to air and food embolism.

In conclusion, catheter ablation of $A F$ is a current personalized case management approach in patients diagnosed with AF. CCT and CMR imaging are modalities that can help identifying patients at high risk for AF progression, can help plan treatment strategy in patients diagnosed with $\mathrm{AF}$, and can evaluate the result of catheter ablation. Since these modalities are essential tool for safe and efficient catheter ablation AF, it is important to understand their roles, technical characteristics, and performance in the management of AF with catheter ablation.

\section{Conflicts of Interest}

The authors have no potential conflicts of interest to disclose.

\section{ORCID iDs}

Sung Ho Hwang

https://orcid.org/0000-0003-1850-0751

Hee-Gone Lee

https://orcid.org/0000-0002-2729-9925

\section{REFERENCES}

1. January CT, Wann LS, Alpert JS, Calkins H, Cigarroa JE, Cleveland JC Jr, et al. 2014 AHA/ACC/HRS guideline for the management of patients with atrial fibrillation: a report of the American College of Cardiology/American Heart Association Task Force on practice guidelines and the Heart 
Rhythm Society. J Am Coll Cardiol 2014;64:e1-e76

2. Kirchhof P, Benussi S, Kotecha D, Ahlsson A, Atar D, Casadei $B$, et al. 2016 ESC Guidelines for the management of atrial fibrillation developed in collaboration with EACTS. Eur Heart $J$ 2016;37:2893-2962

3. Aviles RJ, Martin D0, Apperson-Hansen C, Houghtaling PL, Rautaharju P, Kronmal RA, et al. Inflammation as a risk factor for atrial fibrillation. Circulation 2003;108:3006-3010

4. Nattel S, Allessie M, Haissaguerre M. Spotlight on atrial fibrillation-the 'complete arrhythmia'. Cardiovasc Res 2002; 54:197-203

5. Ehrlich JR, Cha TJ, Zhang L, Chartier D, Melnyk P, Hohnloser $\mathrm{SH}$, et al. Cellular electrophysiology of canine pulmonary vein cardiomyocytes: action potential and ionic current properties. J Physiol 2003;551:801-813

6. Calkins H, Kuck KH, Cappato R, Brugada J, Camm AJ, Chen SA, et al. 2012 HRS/EHRA/ECAS expert consensus statement on catheter and surgical ablation of atrial fibrillation: recommendations for patient selection, procedural techniques, patient management and follow-up, definitions, endpoints, and research trial design: a report of the Heart Rhythm Society (HRS) task force on catheter and surgical ablation of atrial fibrillation. Developed in partnership with the European Heart Rhythm Association (EHRA), a registered branch of the European Society of Cardiology (ESC) and the European Cardiac Arrhythmia Society (ECAS); and in collaboration with the American College of Cardiology (ACC), American Heart Association (AHA), the Asia Pacific Heart Rhythm Society (APHRS), and the Society of Thoracic Surgeons (STS). Endorsed by the governing bodies of the American College of Cardiology Foundation, the American Heart Association, the European Cardiac Arrhythmia Society, the European Heart Rhythm Association, the Society of Thoracic Surgeons, the Asia Pacific Heart Rhythm Society, and the Heart Rhythm Society. Heart Rhythm 2012;9:632-696. e621

7. Haïssaguerre M, Gencel L, Fischer B, Le Métayer P, Poquet $\mathrm{F}$, Marcus FI, et al. Successful catheter ablation of atrial fibrillation. J Cardiovasc Electrophysiol 1994;5:1045-1052

8. Sawhney N, Anousheh R, Chen WC, Narayan S, Feld GK. Fiveyear outcomes after segmental pulmonary vein isolation for paroxysmal atrial fibrillation. Am J Cardiol 2009;104:366-372

9. Bhagirath $\mathrm{P}$, van der Graaf AW, Karim R, van Driel VJ, Ramanna H, Rhode KS, et al. Multimodality imaging for patient evaluation and guidance of catheter ablation for atrial fibrillation - current status and future perspective. Int J Cardiol 2014;175:400-408

10. Njeim M, Desjardins B, Bogun F. Multimodality Imaging for guiding EP ablation procedures. JACC Cardiovasc Imaging 2016;9:873-886

11. Cabrera JA, Sánchez-Quintana D. Cardiac anatomy: what the electrophysiologist needs to know. Heart 2013;99:417-431

12. Mahnkopf C, Badger TJ, Burgon NS, Daccarett M, Haslam TS, Badger CT, et al. Evaluation of the left atrial substrate in patients with lone atrial fibrillation using delayed-enhanced
MRI: implications for disease progression and response to catheter ablation. Heart Rhythm 2010;7:1475-1481

13. Cha YM, Wokhlu A, Asirvatham SJ, Shen WK, Friedman PA, Munger TM, et al. Success of ablation for atrial fibrillation in isolated left ventricular diastolic dysfunction: a comparison to systolic dysfunction and normal ventricular function. Circ Arrhythm Electrophysiol 2011;4:724-732

14. Bisbal F, Guiu E, Calvo N, Marin D, Berruezo A, Arbelo E, et al. Left atrial sphericity: a new method to assess atrial remodeling. Impact on the outcome of atrial fibrillation ablation. J Cardiovasc Electrophysiol 2013;24:752-759

15. Bax JJ, Marsan NA, Delgado V. Non-invasive imaging in atrial fibrillation: focus on prognosis and catheter ablation. Heart 2015;101:94-100

16. Delgado V, Di Biase L, Leung M, Romero J, Tops LF, Casadei B, et al. Structure and function of the left atrium and left atrial appendage: AF and stroke implications. J Am Coll Cardiol 2017;70:3157-3172

17. Maceira AM, Cosín-Sales J, Roughton M, Prasad SK, Pennell DJ. Reference left atrial dimensions and volumes by steady state free precession cardiovascular magnetic resonance. $J$ Cardiovasc Magn Reson 2010;12:65

18. Kistler PM, Sanders P, Fynn SP, Stevenson IH, Spence SJ, Vohra JK, et al. Electrophysiologic and electroanatomic changes in the human atrium associated with age. $\mathrm{J} \mathrm{Am}$ Coll Cardiol 2004;44:109-116

19. Marrouche NF, Wilber D, Hindricks G, Jais P, Akoum N, Marchlinski $F$, et al. Association of atrial tissue fibrosis identified by delayed enhancement MRI and atrial fibrillation catheter ablation: the DECAAF study. JAMA 2014;311:498-506 20. Oakes RS, Badger TJ, Kholmovski EG, Akoum N, Burgon NS, Fish EN, et al. Detection and quantification of left atrial structural remodeling with delayed-enhancement magnetic resonance imaging in patients with atrial fibrillation. Circulation 2009;119:1758-1767

21. McGann CJ, Kholmovski EG, Oakes RS, Blauer JJ, Daccarett $M$, Segerson $N$, et al. New magnetic resonance imagingbased method for defining the extent of left atrial wall injury after the ablation of atrial fibrillation. J Am Coll Cardiol 2008:52:1263-1271

22. Naksuk N, Padmanabhan D, Yogeswaran V, Asirvatham SJ. Left atrial appendage: embryology, anatomy, physiology, arrhythmia and therapeutic intervention. JACC Clin Electrophysiol 2016;2:403-412

23. Wazni 0, Wilkoff B, Saliba W. Catheter ablation for atrial fibrillation. N Engl J Med 2011;365:2296-2304

24. Manning WJ, Weintraub RM, Waksmonski CA, Haering JM, Rooney PS, Maslow AD, et al. Accuracy of transesophageal echocardiography for identifying left atrial thrombi. A prospective, intraoperative study. Ann Intern Med 1995;123:817-822

25. Patel A, Au E, Donegan K, Kim RJ, Lin FY, Stein KM, et al. Multidetector row computed tomography for identification of left atrial appendage filling defects in patients undergoing 
pulmonary vein isolation for treatment of atrial fibrillation: comparison with transesophageal echocardiography. Heart Rhythm 2008;5:253-260

26. Lotz J, Meier C, Leppert A, Galanski M. Cardiovascular flow measurement with phase-contrast MR imaging: basic facts and implementation. Radiographics 2002;22:651-671

27. Hwang SH, Oh YW, Kim MN, Park SM, Shim WJ, Shim J, et al. Relationship between left atrial appendage emptying and left atrial function using cardiac magnetic resonance in patients with atrial fibrillation: comparison with transesophageal echocardiography. Int J Cardiovasc Imaging 2016;32 Suppl 1:163-171

28. Hwang SH, Roh SY, Shim J, Choi JI, Kim YH, Oh YW. Atrial fibrillation: relationship between left atrial pressure and left atrial appendage emptying determined with velocity-encoded cardiac MR imaging. Radiology 2017;284:381-389

29. Echocardiographic predictors of stroke in patients with atrial fibrillation: a prospective study of 1066 patients from 3 clinical trials. Arch Intern Med 1998;158:1316-1320

30. Kirchhof P, Breithardt G, Aliot E, Al Khatib S, Apostolakis $S$, Auricchio A, et al. Personalized management of atrial fibrillation: Proceedings from the fourth Atrial Fibrillation competence NETwork/European Heart Rhythm Association consensus conference. Europace 2013;15:1540-1556

31. Banerjee A, Taillandier S, Olesen JB, Lane DA, Lallemand B, Lip GY, et al. Ejection fraction and outcomes in patients with atrial fibrillation and heart failure: the Loire Valley Atrial Fibrillation Project. Eur J Heart Fail 2012;14:295-301

32. Allessie MA, de Groot NM, Houben RP, Schotten U, Boersma E, Smeets JL, et al. Electropathological substrate of longstanding persistent atrial fibrillation in patients with structural heart disease: longitudinal dissociation. Circ Arrhythm Electrophysiol 2010;3:606-615

33. Sibley CT. Characterization of ventricular myocardium in atrial fibrillation: looking where the light is best. JACC CardiovasC Imaging 2014;7:12-13

34. Addison D, Farhad H, Shah RV, Mayrhofer T, Abbasi SA, John RM, et al. Effect of late gadolinium enhancement on the recovery of left ventricular systolic function after pulmonary vein isolation. J Am Heart Assoc 2016;5: pii: e003570

35. Suksaranjit P, Akoum N, Kholmovski EG, Stoddard GJ, Chang L, Damal K, et al. Incidental LV LGE on CMR imaging in atrial fibrillation predicts recurrence after ablation therapy. JACC Cardiovasc Imaging 2015;8:793-800

36. Avitall B, Bi J, Mykytsey A, Chicos A. Atrial and ventricular fibrosis induced by atrial fibrillation: evidence to support early rhythm control. Heart Rhythm 2008;5:839-845

37. Iles L, Pfluger H, Phrommintikul A, Cherayath J, Aksit P, Gupta SN, et al. Evaluation of diffuse myocardial fibrosis in heart failure with cardiac magnetic resonance contrastenhanced T1 mapping. J Am Coll Cardiol 2008;52:1574-1580

38. Neilan TG, Mongeon FP, Shah RV, Coelho-Filho 0, Abbasi SA, Dodson JA, et al. Myocardial extracellular volume expansion and the risk of recurrent atrial fibrillation after pulmonary vein isolation. JACC Cardiovasc Imaging 2014;7:1-11

39. Wagner M, Butler C, Rief M, Beling M, Durmus T, Huppertz $A$, et al. Comparison of non-gated vs. electrocardiogramgated 64-detector-row computed tomography for integrated electroanatomic mapping in patients undergoing pulmonary vein isolation. Europace 2010;12:1090-1097

40. Blackham KA, Passalacqua MA, Sandhu GS, Gilkeson RC, Griswold MA, Gulani V. Applications of time-resolved MR angiography. AJR Am J Roentgenol 2011;196:W613-W620

41. Kim JS, Oh YW, Shim J, Kim YH, Hwang SH. Optimal cardiac magnetic resonance contrast-enhanced timing robust angiography (CMR-CENTRA) for the three-dimensional reconstruction of the bilateral atria in the electroanatomic mapping (EAM) of atrial fibrillation. Investig Magn Reson Imaging 2017;21:131-138

42. Caponi D, Corleto A, Scaglione M, Blandino A, Biasco L, Cristoforetti $Y$, et al. Ablation of atrial fibrillation: does the addition of three-dimensional magnetic resonance imaging of the left atrium to electroanatomic mapping improve the clinical outcome?: a randomized comparison of Carto-Merge vs. Carto-XP three-dimensional mapping ablation in patients with paroxysmal and persistent atrial fibrillation. Europace 2010;12:1098-1104

43. Tsuchiya T. Three-dimensional mapping of cardiac arrhythmias - string of pearls. Circ J 2012;76:572-581

44. Sra J, Narayan G, Krum D, Malloy A, Cooley R, Bhatia A, et al. Computed tomography-fluoroscopy image integrationguided catheter ablation of atrial fibrillation. J Cardiovasc Electrophysiol 2007;18:409-414

45. Peters DC, Wylie JV, Hauser TH, Kissinger KV, Botnar RM, Essebag V, et al. Detection of pulmonary vein and left atrial scar after catheter ablation with three-dimensional navigatorgated delayed enhancement MR imaging: initial experience. Radiology 2007;243:690-695

46. Ranjan R, Kato R, Zviman MM, Dickfeld TM, Roguin A, Berger $R D$, et al. Gaps in the ablation line as a potential cause of recovery from electrical isolation and their visualization using MRI. Circ Arrhythm Electrophysiol 2011;4:279-286

47. Badger TJ, Daccarett M, Akoum NW, Adjei-Poku YA, Burgon NS, Haslam TS, et al. Evaluation of left atrial lesions after initial and repeat atrial fibrillation ablation: lessons learned from delayed-enhancement MRI in repeat ablation procedures. Circ Arrhythm Electrophysiol 2010;3:249-259

48. Kurotobi T, Iwakura K, Inoue K, Kimura R, Toyoshima Y, Ito $\mathrm{N}$, et al. The significance of the shape of the left atrial roof as a novel index for determining the electrophysiological and structural characteristics in patients with atrial fibrillation. Europace 2011;13:803-808

49. Lee JM, Kim JB, Uhm JS, Pak HN, Lee MH, Joung B. Additional value of left atrial appendage geometry and hemodynamics when considering anticoagulation strategy in patients with atrial fibrillation with low $\mathrm{CHA}_{2} \mathrm{DS}_{2}$-VASc scores. Heart Rhythm 2017;14:1297-1301

50. Kim YG, Shim J, Oh SK, Park HS, Lee KN, Hwang SH, et al. 
Different responses of left atrium and left atrial appendage to radiofrequency catheter ablation of atrial fibrillation: a follow up MRI study. Sci Rep 2018;8:7871

51. Chang SH, Tsao HM, Wu MH, Tai CT, Chang SL, Wongcharoen $\mathrm{W}$, et al. Morphological changes of the left atrial appendage after catheter ablation of atrial fibrillation. J Cardiovasc Electrophysiol 2007;18:47-52

52. Holmes DR Jr, Monahan KH, Packer D. Pulmonary vein stenosis complicating ablation for atrial fibrillation: clinical spectrum and interventional considerations. JACC Cardiovasc Interv 2009;2:267-276

53. Fender EA, Widmer RJ, Hodge D0, Cooper GM, Monahan $\mathrm{KH}$, Peterson LA, et al. Severe pulmonary vein stenosis resulting from ablation for atrial fibrillation: presentation, management, and clinical outcomes. Circulation
2016;134:1812-1821

54. Greenway SC, Yoo SJ, Baliulis G, Caldarone C, Coles J, GrosseWortmann L. Assessment of pulmonary veins after atriopericardial anastomosis by cardiovascular magnetic resonance. J Cardiovasc Magn Reson 2011;13:72

55. Prieto LR, Kawai Y, Worley SE. Total pulmonary vein occlusion complicating pulmonary vein isolation: diagnosis and treatment. Heart Rhythm 2010;7:1233-1239

56. Cappato R, Calkins H, Chen SA, Davies W, Iesaka Y, Kalman $\mathrm{J}$, et al. Updated worldwide survey on the methods, efficacy, and safety of catheter ablation for human atrial fibrillation. Circ Arrhythm Electrophysiol 2010;3:32-38

57. Pollak SJ, Monir G, Chernoby MS, Elenberger CD. Novel imaging techniques of the esophagus enhancing safety of left atrial ablation. J Cardiovasc Electrophysiol 2005;16:244-248 